\title{
Expression and significance of hypoxia-inducible factor-1 $\alpha$ and glucose transporter-1 in laryngeal carcinoma
}

\author{
XIAO-HONG WU ${ }^{1}$, SU-PING CHEN ${ }^{2}$, JIAN-YING MAO ${ }^{1}$, XUE-XIAN JI $^{1}$, \\ HONG-TIAN YAO ${ }^{3}$ and SHUI-HONG ZHOU ${ }^{2}$
}

\begin{abstract}
${ }^{1}$ Department of Otolaryngology, The People's Hospital of Deqing County, Zhejiang (The Cooperative Hospital of The First Affiliated Hospital, College of Medicine, Zhejiang University), Deqing City; ${ }^{2}$ Department of Otolaryngology, The First Affiliated Hospital, College of Medicine, Zhejiang University, Hangzhou; ${ }^{3}$ Department of Pathology, The People's Hospital of Deqing County, Zhejiang (The Cooperative Hospital of The First Affiliated Hospital, College of Medicine, Zhejiang University), Deqing City, P.R. China
\end{abstract}

Received May 13, 2012; Accepted August 14, 2012

DOI: $10.3892 / \mathrm{ol} .2012 .941$

\begin{abstract}
Malignant cells show increased glucose uptake in vitro and in vivo. This process is considered to be mediated by glucose transporters (GLUTs). Hypoxia-inducible factor- $1 \alpha$ $(\mathrm{HIF}-1 \alpha)$ may upregulate GLUT-1 expression. Little is known about the correlation between HIF-1 $\alpha$ and GLUT-1 expression in laryngeal carcinoma. The current study investigated this correlation immunohistochemically, according to various clinical and pathological features, in 49 paraffin-embedded archival tissue blocks from patients with laryngeal squamous cell carcinoma. HIF-1 $\alpha$ and GLUT-1 expression was detected in 63.3 (31/49) and 55.1\% (27/49) of the tumour samples, respectively. HIF-1 $\alpha$ expression was significantly correlated with lymph node classification $(\mathrm{P}=0.018)$, recurrence $(\mathrm{P}=0.02)$ and metastasis $(\mathrm{P}=0.031)$. GLUT-1A expression was significantly associated with recurrence $(\mathrm{P}=0.02)$ and metastasis $(\mathrm{P}=0.01)$. Univariate analyses revealed that HIF- $1 \alpha\left(\chi^{2}=8.2 ; \mathrm{P}=0.004\right)$ and GLUT-1 expression $\left(\chi^{2}=9.0 ; \mathrm{P}=0.003\right)$ were significantly associated with a poorer survival rate. In a multivariate analysis, GLUT-1 expression $(\mathrm{P}=0.006)$ was a significant predictor of poor survival rate, as well as the primary tumour site, lymph node invasion and distant metastasis. Based on Spearman's analysis, GLUT-1 expression and phosphatidylinositol 3-kinase (PI3K) expression were significantly correlated $(\mathrm{r}=0.504 ; \mathrm{P}=0.000)$. This is the first study to demonstrate a significant correlation between GLUT-1 and HIF-1 $\alpha$ expression in laryngeal carcinoma and to show increased GLUT-1 expression as an independent survival
\end{abstract}

Correspondence to: Dr Shui-Hong Zhou, Department of Otolaryngology, The First Affiliated Hospital, College of Medicine, Zhejiang University, 79 Qingchun Road, Zhejiang, Hangzhou 310003, P.R. China

E-mail: zhouyunzhoush@163.com

Key words: hypoxia-inducible factor-1 $\alpha$, glucose transporter-1, laryngeal carcinoma, prognosis rate predictor. These results suggest that GLUT-1 is a potential new therapeutic target for laryngeal carcinoma.

\section{Introduction}

Malignant tumours are considered to be in a hypoxic state (1). Under hypoxic conditions, cancer cells switch from oxygen-dependent glucose metabolism to oxygen-independent glycolysis (2). Malignant cells show increased glucose uptake in vitro and in vivo. This process is considered to be mediated by glucose transporters (GLUTs). Among GLUTs, GLUT-1 is one of the most significant mediators of increased glucose influx into cells (3). The rate of glucose transport via GLUT-1 may be altered under conditions in which the metabolic rate must be adjusted, including during cell division (mitosis and meiosis), differentiation, transformation and nutrient starvation (4). In previous studies (5-11), Glut-1 expression has been correlated with lymph node metastasis, poor survival rate and clinical stage of head and neck carcinoma (HNC).

Hypoxia-inducible factor- $1 \alpha$ (HIF-1 $\alpha$ ), a transcription factor associated with the cellular response to hypoxia (12), upregulates the expression of several hypoxia response genes, including GLUT-1 (1). The overexpression of GLUT-1 increases glucose transport to meet the energy requirements of malignant tumour cells. In numerous types of human cancer, the correlation between HIF-1 $\alpha$ and GLUT-1 expression may promote tumour progression, leading to a poor outcome (1,13-18), although the correlation between HIF-1 $\alpha$ and GLUT-1 expression in colorectal cancer is controversial $(19,20)$.

To the best of our knowledge, only one study exists in the English-language literature with regard to the correlation between HIF-1 $\alpha$ and GLUT-1 expression in laryngeal carcinoma and their association with clinicopathological features (21). This study identified no correlation between GLUT-1 overexpression and clinical outcome parameters of laryngeal carcinoma. A small quantity of studies have investigated HIF-1 $\alpha(22,23)$ or GLUT-1 expression alone $(24,25)$ in laryngeal carcinoma. The present study investigated the corre- 
lation between HIF-1 $\alpha$ and GLUT-1 expression with respect to various clinical and pathological features of laryngeal carcinoma.

\section{Patients and methods}

Patients and tissues. A total of 49 paraffin-embedded archival tissue blocks from patients with laryngeal squamous cell carcinomas were obtained between 2002 and 2009; six blocks were from the surgical pathological files at The People's Hospital of Deqing County (Zhejiang, China) and 43 blocks were from the surgical pathological files at The First Affiliated Hospital, College of Medicine, Zhejiang University (Deqing City, China). A total of 15 paraffinembedded archival tissue blocks from patients with vocal cord polyps and 15 paraffin-embedded archival tissue blocks from patients with vocal cord leukokeratosis were also obtained. Formalin-fixed, paraffin-embedded archival tissues were obtained from institutional and consultation files. One representative paraffin block from each tumour was selected for the immunohistochemical study. Diagnosis was confirmed following blind review of all haematoxylinand eosin-stained sections. None of the patients had received preoperative radiotherapy or chemotherapy. Demographic and clinicopathological data, including gender, age, $\mathrm{T}$ and $\mathrm{N}$ category (as established by the International Union Against Cancer TNM classification 2007, 7th edition) and current and past tobacco and alcohol use were retrospectively collected by reviewing the patient charts. Institutional Review Board approvals were obtained through The People's Hospital of Deqing County and The First Affiliated Hospital, College of Medicine, Zhejiang University.

Immunohistochemistry. Formalin-fixed and paraffin-embedded tissue blocks from primary lesions were cut into $4-\mu \mathrm{m}$ sections and representative sections were analysed immunohistochemically (EliVision ${ }^{\mathrm{TM}}$ Plus IHC kit; Fuzhou Maixin Biotechnology Development Co., Ltd., Fuzhou, China) for HIF-1 $\alpha$ (1:100; Santa Cruz Biotechnology, Santa Cruz, CA, USA) and GLUT-1 (1:50, rabbit polyclonal; Santa Cruz Biotechnology) expression (22). Briefly, the sections were deparaffinised in xylene and rehydrated through graded concentrations of alcohol. Antigen retrieval was performed in a microwave oven for two cycles of $10 \mathrm{~min}$ each. Endogenous peroxidase activity was blocked by incubating the sections in $1.5 \%$ hydrogen peroxide in absolute methanol at room temperature for $10 \mathrm{~min}$. Primary antibodies were applied for $1 \mathrm{~h}$ at room temperature and the sections were washed three times with $0.05 \mathrm{M}$ Tris-buffered saline (TBS, $\mathrm{pH}$ 7.2). Then, $50 \mu \mathrm{l}$ of polymer enhancer were added and following $20 \mathrm{~min}, 50 \mu \mathrm{l}$ of polymerised horseradish peroxidase anti-mouse immunoglobulin $\mathrm{G}$ were added, followed by incubation for $30 \mathrm{~min}$ at room temperature. The sections were washed three times with TBS and the reaction products were visualised with diaminobenzidine (DAB kit; Maixin Biological Technology Ltd., Fujian, China). The sections were counterstained with haematoxylin and eosin, dehydrated and evaluated under a light microscope. As a negative control, samples were incubated using $10 \mathrm{mM}$ TBS ( $\mathrm{pH}$ 7.4) instead of a primary antibody. Erythrocytes in the tissue sections served as the positive control for GLUT-1 expression (5). Nuclear and cytoplasmic HIF-1 $\alpha$ staining was scored as reported previously (22).

Scoring of immunopositive cells. Positive staining for HIF-1 $\alpha$ and GLUT-1 was assessed in 10 high-power fields of each tumour by two pathologists using light microscopy. The mean rate of positive tumour cells was calculated. Positive expression and negative expression were defined as immunostaining of $>10 \%$ and $<10 \%$ of the cancer cells, respectively.

Statistical analysis. Associations between HIF-1 $\alpha$ and GLUT-1 immunostaining and other parameters (age, $\mathrm{T}$ and $\mathrm{N}$ category, tobacco and alcohol use) were analysed using a $\chi^{2}$ test and Fisher's exact test. $\mathrm{P} \leq 0.05$ was considered to indicate a statistically significant difference. The correlation between HIF-1 $\alpha$ and GLUT-1 was analysed by Spearman's correlation. Overall survival rate (OS), defined as the time from surgery until mortality from any cause, was plotted as a Kaplan-Meier curve. Univariate survival rate analysis was performed using a log-rank test and multivariate analysis was performed using Cox proportional-hazards regression analysis. All analyses were conducted using SPSS for Windows (ver. 19.0; SPSS, Inc., Chicago, IL, USA).

\section{Results}

Patient characteristics. Of the 49 laryngeal carcinoma tissue samples, 43 were from male patients and 6 were from female patients, yielding a male to female ratio of $\sim 7: 1$. The median age of the 49 patients was 60.8 years (range, $32-81$ ). Of the 49 laryngeal carcinomas, $32(65.3 \%)$ were located in the glottic area; $14(28.6 \%)$ in the supraglottic area and three $(6.1 \%)$ in the subglottic area. At the time of diagnosis, 12 patients (24.5\%) presented with lymph node metastases. Further details of the patients and tumours are presented in Table I.

The average follow-up period was 42.6 months (range, 13-181) and 4 patients were lost to follow-up. A total of 20 patients $(40.8 \%)$ developed recurrence and seven (14.3\%) developed distant metastases. In total, 6 patients (12.2\%) succumbed to distant metastasis and local recurrence and seven (14.3\%) succumbed to local recurrence of the disease. Among the 13 deceased patients, 9 had tumours in the supraglottic area and 4 had tumours in the glottic area $(\mathrm{P}<0.001)$. In total, 36 were alive at the last follow-up.

HIF-1 $\alpha$ and GLUT-1 expression in laryngeal carcinoma and associations with clinicopathological variables and prognosis. Staining for HIF-1 $\alpha$ occurred in a granular and diffuse pattern localised mainly in the cytoplasm of cancer cells, although staining was occasionally nuclear and cytoplasmic (Fig. 1A). HIF-1 $\alpha$ expression was detected in $63.3 \%$ (31/49) of the tumours. HIF-1 $\alpha$ expression was higher in laryngeal carcinoma than in cord polyp or vocal cord leukokeratosis $(\mathrm{P}<0.05$; Table II). HIF-1 $\alpha$ expression did not differ significantly according to patient gender, age, tumour site, $\mathrm{T}$ classification, pathological type or histological grade (Table I). However, HIF-1 $\alpha$ expression was significantly correlated with lymph node classification $(\mathrm{P}=0.018)$, recurrence $(\mathrm{P}=0.02)$ and metastasis $(\mathrm{P}=0.031)$ (Table I). 
Table I. Clinicopathological findings of 49 laryngeal carcinomas.

\begin{tabular}{|c|c|c|c|c|c|c|c|}
\hline Characteristics & No. $(\%)$ & HIF- $\alpha$-positive (\%) & $\chi^{2}$ & P-value & GLUT-1-positive (\%) & $\chi^{2}$ & P-value \\
\hline \multicolumn{8}{|l|}{ Gender } \\
\hline Male & $43(87.8)$ & $29(59.2)$ & \multirow[t]{2}{*}{1.37} & \multirow[t]{2}{*}{0.24} & $24(49.0)$ & \multirow[t]{2}{*}{0.07} & \multirow[t]{2}{*}{0.56} \\
\hline Female & $6(12.2)$ & $2(4.1)$ & & & $3(6.1)$ & & \\
\hline \multicolumn{8}{|l|}{ Age (years) } \\
\hline$<60$ & $25(51.0)$ & $14(28.6)$ & \multirow[t]{2}{*}{0.61} & \multirow[t]{2}{*}{0.44} & $12(24.5)$ & \multirow[t]{2}{*}{1.05} & \multirow[t]{2}{*}{0.23} \\
\hline$\geq 60$ & $24(49.0)$ & $17(34.7)$ & & & $15(30.6)$ & & \\
\hline \multicolumn{8}{|l|}{ Primary tumour site } \\
\hline Supraglottic & $14(28.6)$ & $10(20.4)$ & \multirow[t]{3}{*}{0.64} & \multirow[t]{3}{*}{0.73} & $10(20.4)$ & \multirow[t]{3}{*}{2.61} & \multirow[t]{3}{*}{0.28} \\
\hline Glottic & $32(65.3)$ & $19(38.8)$ & & & $15(30.6)$ & & \\
\hline Subglottic & $3(6.1)$ & $2(4.1)$ & & & $2(4.1)$ & & \\
\hline \multicolumn{8}{|l|}{ Tumour classification } \\
\hline $\mathrm{T} 1$ & $18(36.7)$ & $8(16.3)$ & \multirow[t]{4}{*}{$0.136^{\mathrm{a}}$} & & $8(16.3)$ & \multirow[t]{4}{*}{$0.53^{\mathrm{a}}$} & \\
\hline $\mathrm{T} 2$ & $23(46.9)$ & $16(32.7)$ & & & $13(26.5)$ & & \\
\hline $\mathrm{T} 3$ & $7(14.3)$ & $6(12.2)$ & & & $5(10.2)$ & & \\
\hline $\mathrm{T} 4 \mathrm{a}$ & $1(2.0)$ & $1(2.0)$ & & & $1(2.0)$ & & \\
\hline \multicolumn{8}{|l|}{ Lymph node metastasis } \\
\hline Yes & $12(24.5)$ & $11(22.4)$ & \multirow[t]{2}{*}{6.50} & \multirow[t]{2}{*}{0.018} & $9(18.4)$ & \multirow[t]{2}{*}{2.66} & \multirow[t]{2}{*}{0.10} \\
\hline No & $37(75.5)$ & $20(40.8)$ & & & $18(36.7)$ & & \\
\hline \multicolumn{8}{|l|}{ Pathological type } \\
\hline $\mathrm{SCC}$ & $46(93.9)$ & $30(61.2)$ & \multirow[t]{2}{*}{$0.30^{\mathrm{a}}$} & & $26(53.1)$ & \multirow[t]{2}{*}{0.61} & \multirow[t]{2}{*}{0.42} \\
\hline $\mathrm{ACC}$ & $3(6.1)$ & $1(2.0)$ & & & $1(2.0)$ & & \\
\hline \multicolumn{8}{|l|}{ Histological grade } \\
\hline Well-differentiated & $24(49.0)$ & $13(26.5)$ & \multirow[t]{3}{*}{3.19} & 0.20 & $12(24.5)$ & 2.71 & 0.29 \\
\hline Moderately differentiated & $13(26.5)$ & $8(16.3)$ & & & $6(12.2)$ & & \\
\hline Poorly differentiated & $12(24.5)$ & $10(20.4)$ & & & $9(18.4)$ & & \\
\hline Recurrence & & & & & & & \\
\hline Yes & $20(40.8)$ & $17(34.7)$ & 5.38 & 0.02 & $15(30.6)$ & 5.59 & 0.02 \\
\hline No & $29(59.2)$ & $14(28.6)$ & & & $12(24.5)$ & & \\
\hline Metastasis & & & $0.031^{\mathrm{a}}$ & & & $0.01^{\mathrm{a}}$ & \\
\hline Yes & $7(14.3)$ & $7(14.3)$ & & & $7(14.3)$ & & \\
\hline No & $42(85.7)$ & $24(49.0)$ & & & $20(40.8)$ & & \\
\hline
\end{tabular}

SCC, squamous cell carcinoma; ACC, adenoid cystic carcinoma; ${ }^{a}$ Fisher's exact test. HIF-1 $\alpha$, hypoxia-inducible factor- $1 \alpha$; GLUT-1, glucose transporter-1.

Staining for GLUT-1 occurred in a diffuse pattern localised in the membrane of cancer cells (Fig. 1B). GLUT-1 expression was detected in $55.1 \%$ (27/49) of the tumours and was higher in laryngeal carcinoma than in cord polyp or vocal cord leukokeratosis $(\mathrm{P}<0.05$; Table II). GLUT-1 expression did not differ significantly according to patient age, tumour site, $\mathrm{T}$ classification, pathological type, histological grade or lymph node classification. However, GLUT-1 expression was significantly correlated with recurrence $(\mathrm{P}=0.02)$ and metastasis $(\mathrm{P}=0.01)$ (Table $\mathrm{I})$.

The median OS was 134 months [95\% confidence interval (CI), 113-154]. The 3- and 5-year OS rates were $77.0 \%$ [standard error (SE), 0.06] and 69.0\% (SE, 0.07), respectively. Univariate analysis revealed that improved survival rate was significantly associated with a primary cancer site in the glottic area $\left(\chi^{2}=15.5, \mathrm{P}<0.001\right)$, well-differentiated carcinoma $\left(\chi^{2}=8.4, \mathrm{P}=0.004\right)$, early $\mathrm{T}$ classification $(\mathrm{T} 1+\mathrm{T} 2$; $\left.\chi^{2}=10.2, \mathrm{P}=0.001\right)$, no lymph node involvement $\left(\chi^{2}=33.1\right.$, $\mathrm{P}<0.001)$, no recurrence $\left(\chi^{2}=31.0, \mathrm{P}<0.001\right)$ and no metastasis $\left(\chi^{2}=20.9, \mathrm{P}<0.001\right)$. HIF-1 $\alpha$ expression (Fig. $2 ; \chi^{2}=8.2$, $\mathrm{P}=0.004$ ) and GLUT-1 expression (Fig. $3 ; \chi^{2}=9.0, \mathrm{P}=0.003$ ) were significantly associated with a poorer survival rate in a univariate analysis. In a multivariate analysis, significant predictors of poor survival rate included a primary cancer site in the supraglottic and subglottic areas $(\mathrm{P}=0.038)$, lymph node invasion $(\mathrm{P}=0.007)$, distant metastasis $(\mathrm{P}=0.006)$ and GLUT-1 expression $(\mathrm{P}=0.006)$.

Correlation between HIF-1 $\alpha$ and GLUT-1 expression. Spearman's analysis revealed a significant correlation between GLUT-1 and phosphatidylinositol 3-kinase (PI3K) expression $(\mathrm{r}=0.504, \mathrm{P}=0.000)$. 
Table II. Immunohistochemical results of HIF-1 $\alpha$ and GLUT-1 in laryngeal carcinomas, cord polyp and vocal cord leukokeratosis.

\begin{tabular}{|c|c|c|c|c|c|c|c|}
\hline \multirow[b]{2}{*}{ Group } & \multirow[b]{2}{*}{$\mathrm{n}$} & \multicolumn{2}{|c|}{ HIF- $1 \alpha$} & \multirow[b]{2}{*}{ P-value } & \multicolumn{2}{|c|}{ GLUT-1 } & \multirow[b]{2}{*}{ P-value } \\
\hline & & Positive & Negative & & Positive & Negative & \\
\hline Cord polyp & 15 & 0 & $15^{\mathrm{a}}$ & $0.000^{\mathrm{a}}$ & 0 & $15^{\mathrm{a}}$ & $0.000^{\mathrm{a}}$ \\
\hline Leukokeratosis & 15 & 2 & $13^{\mathrm{b}}$ & $0.001^{\mathrm{b}}$ & 3 & $12^{\mathrm{b}}$ & $0.02^{\mathrm{b}}$ \\
\hline Laryngeal carcinomas & 49 & 31 & 18 & & 27 & 22 & \\
\hline
\end{tabular}

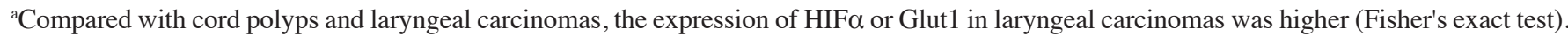
${ }^{\mathrm{b} C o m p a r e d ~ w i t h ~ l e u k o k e r a t o s i s ~ a n d ~ l a r y n g e a l ~ c a r c i n o m a s, ~ t h e ~ e x p r e s s i o n ~ o f ~ H I F ~} \alpha$ or Glut1 in layngeal carcinomas was higher (Fisher's exact test). HIF-1 $\alpha$, hypoxia-inducible factor-1 $\alpha$; GLUT-1, glucose transporter-1.
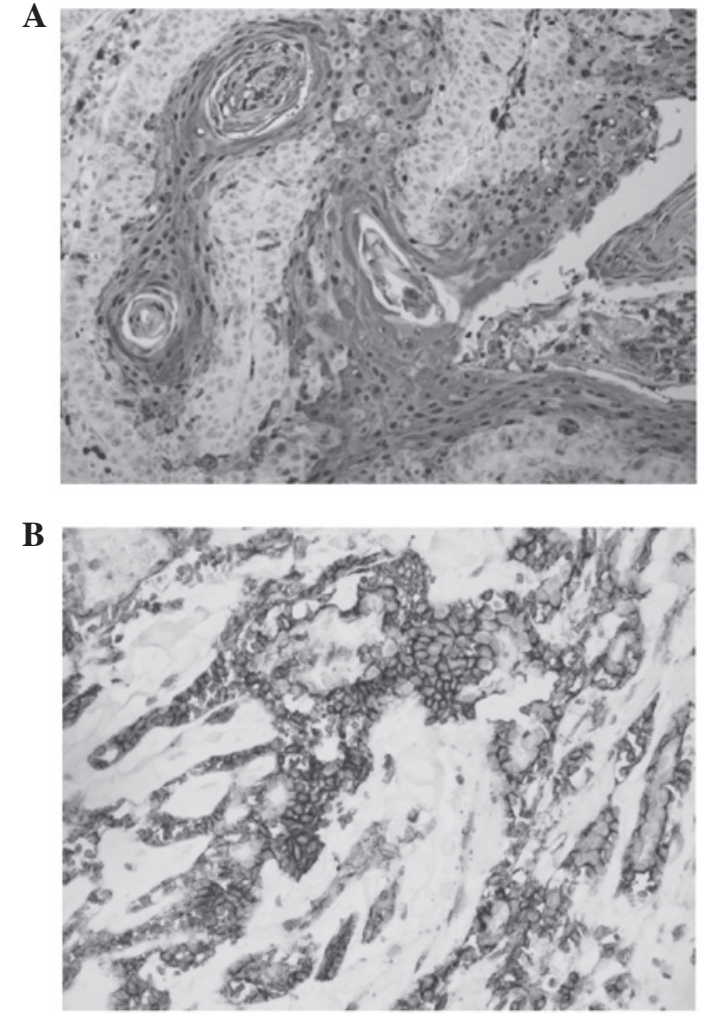

Figure 1. (A) Immunohistochemical staining revealed that HIF-1 $\alpha$ existed in a granular and diffuse pattern localised mainly to the cytoplasm of cancer cells and (B) staining for GLUT-1 was observed in a diffuse pattern localised to the membrane of cancer cells (EliVision, $\mathrm{x} 40$ ). HIF-1 $\alpha$, hypoxia-inducible factor-1 $\alpha$; GLUT-1, glucose transporter-1.

\section{Discussion}

Hypoxia, a common feature of malignancy and particularly of solid tumours, is thought to promote tumour invasiveness and metastasis (26). HIF is a key regulator of cellular responses to hypoxia (12). It targets the genes involved in tumour cell energy metabolism, angiogenesis, tumour metastasis, ion metabolism and catecholamine metabolism, thereby influencing the expression of proteins, including erythropoietin, vascular endothelial growth factor, GLUT-1, glyceraldehyde 3-phosphate dehydrogenase, inducible nitric oxide synthase, insulin-like growth factor-2, tyrosine hydroxylase and glycolytic enzymes (27). HIF-1 $\alpha$ and GLUT-1 are the intrinsic

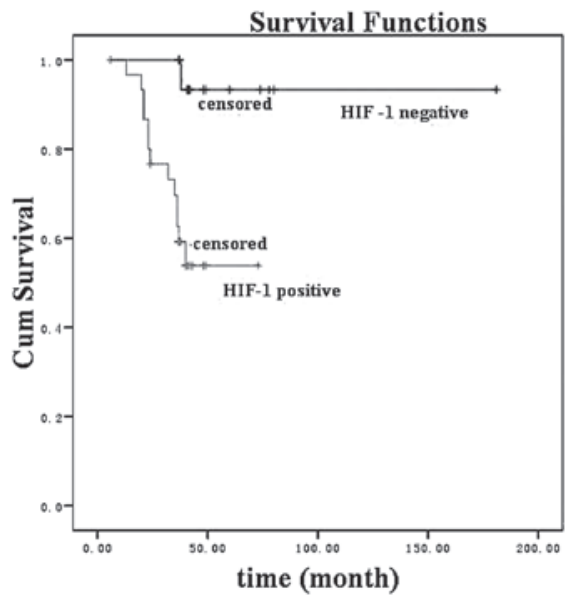

Figure 2. HIF-1 $\alpha$-positive expression was significantly associated with a poorer survival rate in a univariate analysis $\left(\chi^{2}=8.2, \mathrm{P}=0.004\right) . \mathrm{HIF}-1 \alpha$, hypoxia-inducible factor- $1 \alpha$. Cum, cumulative.

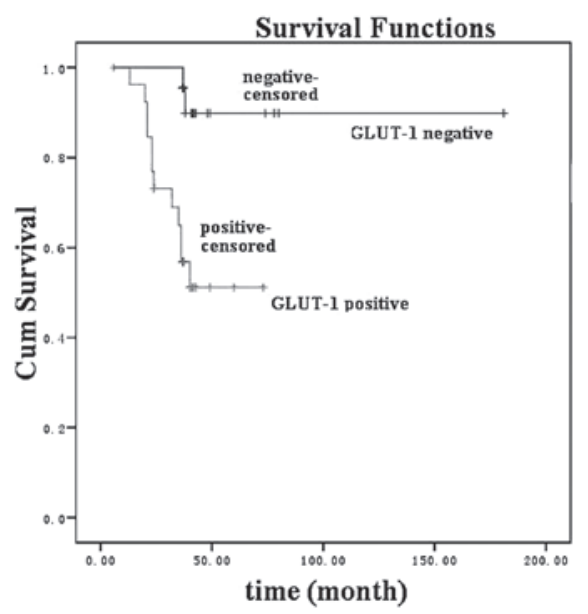

Figure 3. GLUT-1-positive expression was significantly associated with a poorer survival rate in a univariate analysis $\left(\chi^{2}=9.0, \mathrm{P}=0.003\right)$. GLUT-1, glucose transporter-1. Cum, cumulative.

hypoxia markers that have been studied the most in various tumours (13-18). Nevertheless, few studies have investigated the value of HIF-1 $\alpha(22,23,28,29)$ or GLUT-1 expression $(24,25)$ alone for the prediction of clinical outcome and survival rate of laryngeal carcinoma and, to the best of our knowledge, there is 
only one study in the English-language literature with regard to the correlation between HIF-1 $\alpha$ and GLUT-1 expression in laryngeal carcinoma (21).

In a previous study, 67.5\% (27/40) of patients with laryngeal carcinoma were immunopositive for HIF-1 $\alpha$ and HIF-1 $\alpha$ expression was associated with $\mathrm{T}$ stage and lymph node metastasis (22). Similarly, in the present study, the overexpression of HIF-1 $\alpha$ was immunohistochemically detected in $63.3 \%$ (31) of another 49 laryngeal carcinomas and HIF-1 $\alpha$ expression was significantly correlated with lymph node classification, recurrence and metastasis. Yu et al revealed that HIF-1 $\alpha$ was correlated with the clinical stage of laryngeal cancer and lymph node metastasis (23). Wildeman et al suggested that the effect of hypoxia-related proteins, including carbonic anhydrase IX and HIF-1 $\alpha$, on an increased risk for local recurrence of laryngeal carcinoma is stronger following radiotherapy (29). Cabanillas et al reported a significant positive correlation between HIF-1 $\alpha$ and T classification, but no association was observed with other clinicopathological variables or with the prognosis of supraglottic laryngeal squamous cell carcinoma (28). Although HIF-1 $\alpha$ expression was significantly associated with a poorer survival rate in a univariate model in the present study, multivariate analysis revealed no significant association. These apparent discrepancies concerning the correlation between HIF-1 $\alpha$ and survival rate may be attributable to variations in therapeutics or in patient populations, as the disease course and prognosis of head and neck squamous cell carcinoma are known to differ regionally and different patients may carry distinct genetic alterations (28). These limitations may make studies of HIF-1 $\alpha$ in head and neck squamous cell carcinoma susceptible to bias (28).

In a previous study of GLUT-1 expression in laryngeal carcinoma, the expression of GLUT-1 mRNA and protein was increased in laryngeal carcinoma Hep-2 cells and an antisense oligonucleotide against GLUT-1 mRNA reduced the expression of GLUT-1 mRNA and protein, thus inhibiting glucose uptake and cell growth in Hep-2 cells (25). Based on these results, it was suggested that GLUT-1 is a potential therapeutic target for strategies designed to inhibit the progression of laryngeal cancer (25). The present study also demonstrated the overexpression of GLUT-1 in laryngeal carcinoma tissues and there was a significant correlation between GLUT-1 expression and recurrence and metastasis. In univariate and multivariate analyses, increased GLUT-1 expression was significantly associated with a poorer survival rate. GLUT-1 may serve as an independent survival rate predictor, similar to the primary tumour site, lymph node invasion and distant metastasis of laryngeal carcinoma in the present series. The present study provides further support for considering GLUT-1 as a new therapeutic target for laryngeal carcinoma.

In normal cells, HIF-1 $\alpha$ upregulates GLUT-1 expression in response to hypoxic injury (20). In cancer cells, the HIF-1 $\alpha$-induced increase in GLUT-1 serves to provide for the energy requirements of malignant tumour cells. However, certain studies do not reflect this phenomenon. Schrijvers et al reported that there was no significant correlation between GLUT-1 and HIF-1 $\alpha$ expression detected immunohistochemically in 91 stage T1-T2 glottic laryngeal carcinomas treated with radiotherapy and that only HIF- $1 \alpha$ was a predictor of poor survival rate (21). This is contrary to the results of the present study. Contradictory results have also been revealed among studies of other types of cancer and the reason for this remains unknown. Yasuda et al suggested that GLUT-1 expression is not fully regulated by HIF-1 $\alpha$ in ovarian adenocarcinoma. Heterogeneous GLUT-1 expression cannot be satisfactorily explained solely through regulation by HIF-1 $\alpha$ and GLUT-1 overexpression may be more strongly affected by micro-environmental conditions (1). Koukourakis et al identified no association between HIF-1 $\alpha$ and GLUT-1 expression and clinicopathological characteristics in colorectal cancer, reporting GLUT-1 immunoreactivity in not only cancer cells but also the endothelium (19). Wincewicz et al reported that HIF-1 $\alpha$ expression was correlated with GLUT-1 expression in colorectal cancer and suggested that HIF-1 $\alpha$-dependent induction of GLUT-1 is difficult to demonstrate, given that HIF-1 $\alpha$ is detected mainly in the cytoplasm, while it exerts its transcriptional activity in the nucleus (20). In renal cell carcinoma, Lidgren et al revealed that HIF-1 $\alpha$ and GLUT-1 expression levels were significantly correlated with chromophobe renal cell carcinoma (cRCC), but not with papillary renal cell carcinoma (pRCC) (17). In addition, GLUT-1 was overexpressed mainly in cRCC, but not in pRCC, suggesting that other pathways for glucose metabolism are involved in various types of RCC (17).

Thus, numerous factors, including histopathological type, immunohistochemical techniques, tumour stage, sample number and other transcriptional regulators, may affect the correlation between HIF-1 $\alpha$ and GLUT-1 expression in types of cancer and the correlation between their expression and clinicopathological variables and cancer prognosis. HIF-1 $\alpha$ and GLUT-1 expression in carcinomas requires further study.

The current study reports the first finding of a significant correlation between GLUT-1 and HIF-1 $\alpha$ expression in laryngeal carcinoma. Overexpression of HIF-1 $\alpha$ was significantly correlated with lymph node classification, recurrence and metastasis. Increased GLUT-1 expression was significantly associated with recurrence and metastasis of laryngeal carcinoma and may serve as an independent survival rate predictor. The present results further indicate that GLUT-1 may be a potential new therapeutic target for laryngeal carcinoma.

\section{Acknowledgements}

This study was supported by the Science and Technology Bureau of Deqing County, Zhejiang Province, China (No. 2009Ny01), Department of Science and Technology of Zhejiang Provincial (contract grant number: 2009C33026), Health Bureau of Zhejiang Province (contract grant number: 2010KYA062) and National Natural Science Foundation of China (No. 81172562).

\section{References}

1. Yasuda M, Miyazawa M, Fujita M, et al: Expression of hypoxia inducible factor- $1 \alpha$ (HIF-1 $\alpha$ ) and glucose transporter-1 (GLUT-1) in ovarian adenocarcinomas: difference in hypoxic status depending on histological character. Oncol Rep 19: 111-116, 2008.

2. Havelund BM, Sørensen FB, Lindebjerg J, Spindler KL and Jakobsen A: Pretreatment HIF-1 $\alpha$ and GLUT-1 expressions do not correlate with outcome after preoperative chemoradiotherapy in rectal cancer. Anticancer Res 31: 1559-1565, 2011. 
3. Gu J, Yamamoto H, Fukunaga H, et al: Correlation of GLUT-1 overexpression, tumor size, and depth of invasion with 18F-2-fluoro-2-deoxy-D-glucose uptake by positron emission tomography in colorectal cancer. Dig Dis Sci 51: 198-205, 2006.

4. Merrall NW, Plevin R and Gould GW: Growth factors, mitogens, oncogenes and the regulation of glucose transport. Cell Signal 5: 667-675, 1993.

5. Zhou S, Wang S, Wu Q, Fan J and Wang Q: Expression of glucose transporter-1 and -3 in the head and neck carcinoma - the correlation of the expression with the biological behaviors. ORL J Otorhinolaryngol Relat Spec 70: 189-194, 2008.

6. Eckert AW, Lautner MH, Taubert H, Schubert J and Bilkenroth U: Expression of Glut-1 is a prognostic marker for oral squamous cell carcinoma patients. Oncol Rep 20: 1381-1385, 2008.

7. Deron P, Vermeersch H, Mees G, Vangestel C, Pauwels P and Van de Wiele C: Expression and prognostic value of glucose transporters and hexokinases in tonsil and mobile tongue squamous cell carcinoma. Histol Histopathol 26: 1165-1172, 2011.

8. Nakajo M, Nakajo M, Tani A, et al: Clinical significance of primary lesion FDG uptake for choice between oesophagectomy and endoscopic submucosal dissection for resectable oesophageal squamous cell carcinomas. Eur Radiol 21: 2396-2407, 2011.

9. Kondo Y, Yoshikawa K, Omura Y, et al: Clinicopathological significance of carbonic anhydrase 9, glucose transporter-1, Ki-67 and p53 expression in oral squamous cell carcinoma. Oncol Rep 25: 1227-1233, 2011.

10. Deron P, Vangestel C, Goethals I, et al: FDG uptake in primary squamous cell carcinoma of the head and neck. The relationship between overexpression of glucose transporters and hexokinases, tumour proliferation and apoptosis. Nuklearmedizin 50: 15-21, 2011.

11. Ayala FR, Rocha RM, Carvalho KC, et al: GLUT1 and GLUT3 as potential prognostic markers for oral squamous cell carcinoma. Molecules 15: 2374-2387, 2010.

12. Pez F, Dayan F, Durivault J, et al: The HIF-1-inducible lysyl oxidase activates HIF-1 via the Akt pathway in a positive regulation loop and synergizes with HIF-1 in promoting tumor cell growth. Cancer Res 71: 1647-1657, 2011.

13. Eckert AW, Lautner MH, Schütze A, Taubert H, Schubert J and Bilkenroth U: Coexpression of hypoxia-inducible factor-1 $\alpha$ and glucose transporter-1 is associated with poor prognosis in oral squamous cell carcinoma patients. Histopathology 58: 1136-1147, 2011.

14. Ogane N, Yasuda M, Shimizu M, et al: Clinicopathological implications of expressions of hypoxia-related molecules in esophageal superficial squamous cell carcinoma. Ann Diagn Pathol 14: 23-29, 2010.

15. Sulkowska M, Wincewicz A, Sulkowski S, Koda M and Kanczuga-Koda L: Relations of TGF-beta1 with HIF-1alpha, GLUT-1 and longer survival of colorectal cancer patients. Pathology 41: 254-260, 2009.
16. Iida T, Yasuda M, Miyazawa M, et al: Hypoxic status in ovarian serous and mucinous tumors: relationship between histological characteristics and HIF-1 $\alpha /$ GLUT-1 expression. Arch Gynecol Obstet 277: 539-546, 2008.

17. Lidgren A, Bergh A, Grankvist K, Rasmuson T and Ljungberg B: Glucose transporter-1 expression in renal cell carcinoma and its correlation with hypoxia inducible factor-1 alpha. BJU Int 101: 480-484, 2008

18. Palit V, Phillips RM, Puri R, Shah T and Bibby MC: Expression of HIF- $1 \alpha$ and Glut-1 in human bladder cancer. Oncol Rep 14 909-913, 2005.

19. Koukourakis MI, Giatromanolaki A, Harris AL and Sivridis E: Comparison of metabolic pathways between cancer cells and stromal cells in colorectal carcinomas: a metabolic survival role for tumor-associated stroma. Cancer Res 66: 632-637, 2006.

20. Wincewicz A, Sulkowska M, Koda M and Sulkowski S: Clinicopathological significance and linkage of the distribution of HIF- $1 \alpha$ and GLUT-1 in human primary colorectal cancer. Pathol Oncol Res 13: 15-20, 2007.

21. Schrijvers ML, van der Laan BF, de Bock GH, et al: Overexpression of intrinsic hypoxia markers HIF1 $\alpha$ and CA-IX predict for local recurrence in stage T1-T2 glottic laryngeal carcinoma treated with radiotherapy. Int J Radiat Oncol Biol Phys 72: 161-169, 2008.

22. Wu XH, Lu YF, Hu XD, et al: Expression of hypoxia inducible factor- $1 \alpha$ and its significance in laryngeal carcinoma. J Int Med Res 38: 2040-2046, 2010.

23. Yu L, Liu Y and Cui Y: Expression of hypoxia inducible factor1alpha and its relationship to apoptosis and proliferation in human laryngeal squamous cell carcinoma. J Huazhong Univ Sci Technolog Med Sci 24: 636-638, 2004.

24. Luo XM, Zhou SH and Fan J: Glucose transporter-1 as a new therapeutic target in laryngeal carcinoma. J Int Med Res 38: 1885-1892, 2010

25. Zhou SH, Fan J, Chen XM, Cheng KJ and Wang SQ: Inhibition of cell proliferation and glucose uptake in human laryngeal carcinoma cells by antisense oligonucleotides against glucose transporter-1. Head Neck 31: 1624-1633, 2009.

26. Weljie AM and Jirik FR: Hypoxia-induced metabolic shifts in cancer cells: moving beyond the Warburg effect. Int J Biochem Cell Biol 43: 981-989, 2011

27. Wan J, Chai H, Yu Z, et al: HIF-1 $\alpha$ effects on angiogenic potential in human small cell lung carcinoma. J Exp Clin Cancer Res 30: 77, 2011.

28. Cabanillas R, Rodrigo JP, Secades P, et al: The relation between hypoxia-inducible factor (HIF)-1 $\alpha$ expression with p53 expression and outcome in surgically treated supraglottic laryngeal cancer. J Surg Oncol 99: 373-378, 2009.

29. Wildeman MA, Gibcus JH, Hauptmann M, et al: Radiotherapy in laryngeal carcinoma: can a panel of 13 markers predict response? Laryngoscope 119: 316-322, 2009. 